\title{
Penggunaan Metode Goal Programming Untuk Optimasi Perancangan Proses Produksi Produk Wingko Babat
}

\author{
Novitasari , Tita Talitha, Dewi Agustini Santoso \\ Program Studi Teknik Industri, Fakultas Teknik, Universitas Dian Nuswantoro Semarang \\ JI. Nakula I No. 5-11, Semarang, Jawa Tengah, 50131 \\ Email: 512201200606@mhs.dinus.ac.id
}

\begin{abstract}
One form of actual problems in the manufacturing industry is how to maximize the value of profit with various constraints or constraints. The problem is not only experienced by big industry but also small industry like in UD. Wingko trip Mr. Moel who is trying to maximize the value of profit by estimating the amount of wingko trips that must be produced because there is a problem of the difference in the amount of production with one of the limits associated with the production capacity. The resulting production difference causes the amount of wingko trip or excess production in certain month. The method of Goal Programming is the one method of optimization with more than one objective that are interconnected with each other or conflicting to solve the problem. This research uses the Goal Programming method to optimize the production amount and maximize the profit of the product, and to forecast the number of forward demand by using the number of the past request to know how many products must be produced. Goal Programming Formulations use forecasting as decision variables for optimization of results in compliance with criteria and constraints. The results show the optimal amount of production in January - December 2017 are 29860 bag wingko original, 24000 bag wingko chocolate chocolate, 26004 bag wingko tripe jackfruit and 18084 bag wingko tripe durian with total profit in 2017 is Rp. 429.736.600.
\end{abstract}

Keywords: Optimization, Goal Programming, Production Process Planning, Forecasting.

\begin{abstract}
Abstrak
Salah satu bentuk permasalahan aktual dalam industri manufaktur adalah bagaimana cara yang tepat dalam memaksimalkan nilai keuntungan dengan berbagai macam konstrain atau batasan. Permasalahan tersebut tidak halnya dialami industri besar saja namun juga industri kecil seperti pada UD. Wingko babat Pak Moel yang sedang berupaya memaksimalkan nilai profit dengan cara memperkirakan besaran jumlah produk wingko babat yang harus diproduksi oleh karena terdapat masalah selisih jumlah produksi dengan salah satu batasan terkait dengan kapasitas produksi. Selisih produksi yang dialami tersebut menyebabkan jumlah produksi wingko babat berlebih ataupun kekurangan pada bulan tertentu. Metode Goal Programming merupakan salah satu metode optimasi dengan lebih dari satu tujuan yang saling berkaitan satu sama lain ataupun saling bertentangan untuk penyelesaian masalah. Penelitian ini menggunakan metode Goal Programming untuk mengoptimalkan jumlah produksi dan memaksimalkan keuntungan dari produk tersebut, serta melakukan peramalan terhadap jumlah permintaan ke depan dengan menggunakan jumlah permintaan masa lalu untuk mengetahui berapa jumlah produk yang harus diproduksi. Formulasi Goal Programming menggunakan peramalan sebagai variabel keputusan untuk optimasi hasil dalam pemenuhan kriteria dan kendala. Hasil penelitian menunjukkan jumlah optimal produksi bulan Januari - Desember 2017 sebesar 29860 bag wingko babat original, 24000 bag wingko babat coklat, 26004 bag wingko babat nangka dan 18084 bag wingko babat durian dengan total keuntungan tahun 2017 sebesar Rp. 429.736.600.
\end{abstract}

Kata kunci: Optimasi, Goal Programming, Perencanaan Proses Produksi, Peramalan 


\section{Applied Industrial Engineering Journal}

Vol.1, No. 1, Desember 2017, pp. 47-52

ISSN 2614-235X (Printed)

ISSN 2615-3033 (Online)

http://publikasi.dinus.ac.id/index.php/aiej/index

\section{Pendahuluan}

Dalam industri banyak hal yang perlu diperhatikan seperti produk, kualitas, mutu dan jumlah banyaknya produksi. Untuk mengoptimalkan laba dibutuhkan suatu perencanaan kapasitas produksi yang baik dan optimal. Perencanaan kapasitas produksi merupakan jumlah maksimum output yang dapat diproduksi dalam satuan waktu tertentu (Yamit,2003). dengan adanya perencanaan produksi, diharapkan perusahaan dapat memperkirakan jumlah produk yang akan di produksi dengan tepat. Sehingga produk yang dihasilkan dapat memenuhi permintaan pasar dan dapat menghasilkan laba maksimum dengan biaya yang minimum.

Usaha Dagang (UD) Wingko Babat Pak Moel yang berkedudukan di Semarang yang bergerak di bidang makanan khas, merupakan usaha yang didirikan oleh lbu Nining. Sebagai UD. produksi wingko yang merupakan makanan khas, secara tidak langsung mereka dituntut untuk memperkenalkan wingko babat ke masyarakat Semarang dan pada umumnya kepada masyarakat luar daerah Semarang. Produk yang dihasilkan oleh UD. wingko Babat Pak Moelada empat jenis wingko yaitu original, durian, nangka, dan coklat. UD. Wingko Babat Pak Moel memproduksi produknya bersifat make to order, yang mana pelaksanaan produksinya berdasarkan permintaan dari konsumen.

Dari hasil pengamatan yang dilakukan kendala yang dihadapi oleh UD. Wingko Babat Pak Moel adalah belum mempunyai perencanaan produksi yang optimal sehingga terjadi ketidaksesuain volume produksi dengan jumlah permintaan yang mengakibatkan keterlambatan dalam penyelesaian order, maka diperlukan perencanaan produksi yang optimal agar tidak terjadi kerugian akibat produk yang berlebihan ataupun terlalu sedikit. Selama ini sistem perencanaan produksi yang dilakukan berdasarkan jumlah permintaan yang ada dan berusaha untuk memenuhi jumlah permintaan pasar. UD. Wingko Babat Pak moel tidak dapat menyimpan bahan baku terlalu banyak dan tidak diperbolehkan melebihkan jumlah produksi karena produk tidak dapat disimpan dan memiliki daya tahan yang sebentar.

Dari data selisih permintaan dan produksi wingko babat pada tahun 2016 menunjukkan bahwa terdapat selisih permintaan dan volume produksi untuk produk wingko babat original dengan rata-rata selisih sebesar $10 \%$ untuk jenis produk wingko babat original, $9 \%$ untuk produk wingko babat durian, $13 \%$ untuk produk wingko babat nangka dan $10 \%$ untuk produk wingko babat coklat. Data tersebut menunjukkan bahwa UD. Wingko Babat Pak Moel menghadapi permasalahan kelebihan dan kekurangan jumlah produksi yang terjadi setiap bulan dan bahkan cukup besar pada bulan tertentu. Dalam hal ini tujuan yang ingin dicapai UD. Wingko Babat Pak Moel yaitu mengurangi kekurangan produksi dan kelebihan produksi, untuk itu selisih diharapkan seminimum mungkin dan menghasilkan laba yang maksimal.

Salah satu metode yang digunakan dalam persoalan optimasi adalah metode Goal Programming. Goal Programming merupakan perluasan dari model Linier Programming, yang mana linier programming merupakan suatu cara untuk menyelesaikan persoalan pengalokasian sumber-sumber yang terbatas seperti tenaga kerja, bahan baku, jam kerja mesin dan sebagainya dengan cara terbaik yang mungkin dilakukan sehingga diperoleh maksimasi yang dapat berupa maksimasi keuntungan atau maksimasi yang berupa minimasi biaya [1]. Sedangkan optimasi merujuk pada studi permasalahan yang mencoba mencari solusi optimal, yaitu penyelesaian yang tidak melanggar batasan-batasan yang ada yang paling mempunyai nilai tujuan terbesar atau terkecil, tergantung dari fungsi tujuannya yaitu maksimal atau minimal [2].

Penggunaan Goal Programming dalam melakukan optimalisasi telah digunakan oleh Anis, dkk [3], Hidayat [4], serta Harijanto [5]. Goal Programming secara otomatis menangkap informasi tentang pencapaian relatif dari tujuan-tujuan yang ada. Sehingga dengan menggunakan Goal Programming dapat memenuhi sasaran-sasaran yang hendak dicapai oleh UD. Wingko Babat Pak Moel.

\section{Metode Penelitian}


Data yang digunakan untuk pengolahan data permintaan tiap jenis wingko babat, harga pokok, harga jual, jam kerja reguler, kecepatan produksi, pemakaian bahan baku dan ketersediaan bahan baku.

Untuk menentukan metode peramalan digunakan software Minitab 16. Sedangkan metode perencanaan produksi yang digunakan dalam penelitian ini adalah Goal Programming dengan menggunakan software LINDO.

Tahapan dalam pengolahan data adalah sebagai berikut:

1. Metode peramalan yang digunakan adalah moving average dan double eksponential smoothing.

2. Formulasi fungsi dengan menggunakan metode Goal Programming.

a. Fungsi Tujuan

- $\quad \mathrm{X} 1=$ Wingko original

- $\quad X 2=$ Wingko Durian

- $\quad X 3=$ Wingko Nangka

- $\quad X 4=$ Wingko Coklat

b. Fungsi kendala

- Ketersediaan jam kerja

- Kecepatan produksi

- Ketersediaan bahan baku

c. Fungsi Sasaran

- Memaksimalkan jumlah produksi

- Memaksimumkan keuntungan

\section{Hasil dan Analisis}

3.1 Peramalan Permintaan

Untuk menentukan metode peramalan yang akan digunakan, lebih dahulu harus digambarkan pola datanya. Kemudian dipilih beberapa metode peramalan yang sesuai dengan pola data yang ada. Hasil peramalan permintaan selama 12 periode menggunakan metode terpilih yaitu Double Exponential Smoothing.

\subsection{Formulasi Model Goal Programming}

Formulasi model Goal Programming permasalahan yang akan diselesaikan adalah penentuan kombinasi produk yang optimal. Dengan demikian, yang menjadi variabel keputusan adalah jumlah masing-masing jenis produk yang akan dibuat, yaitu:

- $\quad X 1=$ Wingko original

- $\quad X 2=$ Wingko Durian

- $\quad X 3=$ Wingko Nangka

- $\quad X 4=$ Wingko Coklat

Adapun tujuan-tujuan yang ingin dicapai UD. Wingko babat pak Moel adalah memenuhi permintaan produk, dan memaksimalkan keuntungan. Demikian fungsi pembatas model untuk mencapai tujuan-tujuan UD. wingko babat pak Moel sebagai berikut:

1. Pembatas target permintaan pasar

Untuk memenuhi target permintaan pasar, maka deviasi negatif dan deviasi positif dari pembatas target permintaan harus diminimumkan.

$$
\begin{aligned}
& X_{1}+d_{1}^{-}-d_{1}^{+}=P_{1 R} \\
& X_{2}+d_{2}^{-}-d_{2}^{+}=P_{2 k} \\
& X_{2}+d_{3}^{-}-d_{3}^{+}=P_{2 k} \\
& X_{4}+d_{4}^{-}-d_{4}^{+}=P_{4 k} \\
& \operatorname{Min} Z=\sum_{i=4}^{4}\left(d_{1}^{-}-d_{1}^{+}\right)
\end{aligned}
$$

2. Pembatas keuntungan penjualan

Pembatas ini bertujuan untuk mencapai target keuntungan dari penjualan yang telah ditetapkan dan bila mungkin dimaksimumkan.

$$
4000_{x 1}+4500_{x 2}+4650_{x a}+4500_{x 4}+d_{5}^{-}-d_{5}^{+}=C_{\mathrm{i}}
$$


$\operatorname{Min} Z=d_{5}^{-}$

3. Pembatas ketersediaan waktu kerja

Pembatas ini bertujuan untuk mencapai target ketersediaan waktu kerja dengan jumlah permintaan yang diharapkan penyimpangan kelebihan jam kerja diusahakan nol.

$2 x_{1}+2,5 x_{2}+2,5 x_{2}+2,5 x_{\mathrm{a}}+d_{6}^{-}-d_{6}^{+}=12360$

$\operatorname{Min} Z=\mathrm{d}_{6}^{+}$

4. Pembatas pemakaian dan ketersediaan bahan baku

Dalam hal ini, sesuai sasaran kelebihan bahan baku diusahakan nol. Untuk itu model kendala Goal Programmingnya adalah:

a. $1_{x 1}+1_{x 2}+1_{x a}+1_{x 4}+a_{7}^{7}-d_{7}^{+}=8500$

b. $0,15_{x 1}+0,15_{x 1}+0,15_{x y}+0,15_{x 4}+d_{g}^{-}-d_{g}^{+}=1200$

c. $0,1_{x 1}+0,1+0,1_{x 3}+0,1_{x 4}+a_{9}^{-}-d_{9}^{+}=800$

d. $4_{x 1}+3_{n 2}+3_{x 2}+3_{x 4}+a_{10}^{-}-d_{10}^{+}=35000$

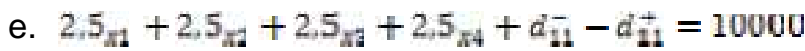

f. $3_{x+1}+3_{x z}+3_{x i}+3_{x 4}+d_{12}-d_{12}^{+}=15000$

g. $5_{x:}+d_{12}^{-}-d_{17}^{+}=8000$

h. $5_{x_{2}}+d_{14}^{-}-d_{14}^{+}=12000$

Berdasarkan pembatas-pembatas tujuan yang diuraikan dan sesuai dengan prioritas yang telah ditetapkan maka formulasi fungsi tujuan perencanaan produksi bulan Januari sebagai berikut:

Min $=r_{1} \Sigma_{l=1}^{4}\left(d_{l}^{-}-d_{l}^{+}\right)+r_{2} d_{9}^{+}+r_{2} d_{6}^{-}+r_{4} \Sigma_{7}^{15} d_{7}^{-}$

Kendala :

-Pembatas Target Permintaan Pasar

$$
\begin{aligned}
& x_{1}+d_{1}^{-}-d_{1}^{+}=2303 \\
& x_{2}+d_{2}^{-}-d_{2}^{+}=1507 \\
& X_{9}+d_{2}^{-}-d_{3}^{+}=1947 \\
& X_{4}+d_{4}^{-}-d_{4}^{+}=1940
\end{aligned}
$$

-Pembatas Keuntungan Penjualan $4000_{x 1}+4500_{x 2}+4650_{x y}+4500_{x 4}+d_{5}^{-}-d_{5}^{+}=33.7 / 7.050$

-Pembatas Ketersediaan Jam Kerja

$$
1.2 x_{1}+1,5 x_{2}+1,5 x_{2}+1,5 x_{4}+d_{6}-d_{6}^{+}=12360
$$

-Pembatas Ketersediaan Bahan Baku

$$
\begin{aligned}
& 1_{a t}+1_{x z}+1_{x a}+1_{x 4}+d_{\overline{7}}-d_{7}^{+}=8500 \\
& 0,15_{x 1}+0,15_{x 1}+0,15_{x 4}+0,15_{x 4}+a_{8}^{-}-d_{a}^{+}=1200 \\
& 0,1_{x 1}+0,1+U, 1_{x 4}+0,1_{x 4}+d_{9}^{-}-d_{9}^{+}=800 \\
& 4_{x t}+3_{x i}+3_{x i}+3_{x 4}+d_{10}-d_{i 0}^{+}=35000 \\
& 2.5_{x 1}+2.5_{x 1}+2.5_{x y}+2.5_{x 4}+d_{11}^{-}-d_{11}^{+}=25000 \\
& 3_{x 1}+3_{x 2}+3_{x 2}+3_{x 4}+d_{12}^{-}-d_{12}^{+}=25000 \\
& 5_{x 2}+d_{13}^{-}-d_{13}^{+}=8000 \\
& 5_{x 2}+d_{14}^{-}-d_{14}^{\overrightarrow{4}}=12000 \\
& 6_{x 4}++d_{15}^{-}-d_{15}^{+}=12000
\end{aligned}
$$

Jumlah produksi dengan menggunakan motode Goal Programming adalah sebagai berikut (Tabel 1)

Tabel 1 Hasil Perencanaan Produksi Menggunakan Goal Programming

\begin{tabular}{|l|l|l|l|l|l|}
\hline \multirow{2}{*}{ No } & \multirow{2}{*}{ Bulan } & \multicolumn{4}{|c|}{ Produksi Wingko Babat } \\
\cline { 3 - 6 } & & Original $($ bag $)$ & Durian $($ bag $)$ & Nangka $($ bag $)$ & Coklat $($ bag $)$ \\
\hline 1 & Januari & 2303 & 1507 & 1947 & 2000 \\
\hline 2 & Februari & 2341 & 1507 & 1987 & 2000 \\
\hline 3 & Maret & 2379 & 1507 & 2027 & 2000 \\
\hline 4 & April & 2417 & 1507 & 2067 & 2000 \\
\hline 5 & Mei & 2455 & 1507 & 2107 & 2000 \\
\hline 6 & Juni & 2492 & 1507 & 2147 & 2000 \\
\hline 7 & Juli & 2530 & 1507 & 2187 & 2000 \\
\hline
\end{tabular}




\begin{tabular}{|l|l|l|l|l|l|}
\hline 8 & Agustus & 2568 & 1507 & 2227 & 2000 \\
\hline 9 & September & 2559 & 1507 & 2267 & 2000 \\
\hline 10 & Oktober & 2568 & 1507 & 2307 & 2000 \\
\hline 11 & November & 2605 & 1507 & 2347 & 2000 \\
\hline 12 & Desember & 2643 & 1507 & 2387 & 2000 \\
\hline Total & 29860 & 18084 & 26004 & 24000 \\
\hline
\end{tabular}

Keuntungan dengan menggunakan metode Goal Programming adalah sebagai berikut (Tabel 2):

Tabel 2 Penyimpangan antara Target Keuntungan dengan Solusi Optimal Goal Programming

\begin{tabular}{|l|l|l|l|}
\hline \multirow{2}{*}{ No } & \multirow{2}{*}{ Bulan } & \multicolumn{2}{|c|}{ Keuntungan } \\
\cline { 3 - 4 } & Januari & Rp33.777.050 & Solusi Optimal \\
\hline 1 & Februari & Rp34.115.050 & Rp34.047.050 \\
\hline 2 & Maret & Rp34.448.550 & Rp34.723.050 \\
\hline 3 & April & Rp34.782.050 & Rp35.061.050 \\
\hline 4 & Mei & Rp35.111.050 & Rp35.399.050 \\
\hline 5 & Rp35.445.050 & Rp35.733.050 \\
\hline 6 & Juni & Rp36.071.050 \\
\hline 7 & Juli & Rp35.778.550 & Rp36.05 \\
\hline 8 & Agustus & Rp36.112.050 & Rp36.409.050 \\
\hline 9 & September & Rp36.450.050 & Rp36.559.050 \\
\hline 10 & Oktober & Rp36.783.550 & Rp36.781.050 \\
\hline 11 & Nopember & Rp37.117.050 & Rp37.115.050 \\
\hline 12 & Desember & Rp37.450.550 & Rp37.453.050 \\
\hline Total & & Rp427.370.600 & Rp429.736.600 \\
\hline
\end{tabular}

Salah satu sasaran dalam perencanaan produksi yang optimal memaksimalkan keuntungan. Pada tabel 2 dapat dilihat target yang ingin ditetapkan sesuai dengan perencanaan sebelumnya sebelumnya bahkan keuntungan melebihi target sasaran dengan kombinasi optimal yang lebih menguntungkan dengan menggunakan perencanaan Goal Programming. total keuntungan dengan menggunakan perencanaan Goal Programming selama tahun 2017 adalah p. 429.736.600. Dari data keuntungan pada periode sebelumnya pada tahun 2016 didapatkan keuntungan sebesar Rp. 376.840.300,- dan adapaun keuntungan yang didapatkan dengan menggunakan metode Goal Programming untuk periode tahun 2017 keuntungan diperoleh Rp. 429.736.600. Jadi, selisih peningkatan keuntungannya yaitu sebesar Rp. 52.896.300.

\section{Kesimpulan}

Setelah dilakukannya pengolahan dan analisis pemecahan masalah, maka dapat ditarik kesimpulan adalah berdasarkan perhitungan Goal Programming didapatkan jumlah optimal produksi pada tahun 2017 yaitu sebesar 29860 bag wingko babat original, 18084 bag wingko babat durian, 26004 bag wingko babat nangka dan 24000 bag wingko babat coklat. Keuntungan perusahaan jika membuat produk sesuai dengan solusi optimal Goal Programming diperoleh keuntungan sebesar $\mathrm{Rp}$ 429.736.600. ada beberapa saran dari hasil penelitian ini antara lain: (1) UD. Wingko Babat Pak Moel dapat menggunakan metode Goal Programming sebagai solusi untuk menentukan produksi yang optimal dalam perencanaan produksi, karena metode ini dapat mengakomodasi beberapa tujuan yang ingin di capai. (2) UD. Wingko Babat Pak Moel disarankan memaksimalkan pemakaian bahan baku tertentu untuk mengurangi penumpukan bahan baku. (3) Adapun pemakaian jam kerja masih lebih kecil dibandingkan dengan jumlah ketersediaan jam kerja, sebaiknya UD. mengurangi ketersediaan jam kerja agar lebih mengurangi biaya produksi. (4) Peneliti selanjutnya, sebaiknya lebih teliti dalam perumusan fungsi tujuan dan fungsi kendala.

\section{Referensi}

[1] Tjuju T., Dimyati, dan Dimyati, A. 2002. Operation Research : Model-model Pengambilan Keputusan. Bandung: Sinar Baru Algesindo. 
[2] Hillier, F. dan Lieberman, G. 1994. Pengantar Riset Operasi. Jilid 1 Edisi Kelima. Jakarta: Penerbit Erlangga.

[3] Anis, M., S. Nandiroh, dan Agustin D.U. 2007. Optimasi Perencanaan Produksi Dengan Metode Goal Programming. Surakarta: Jurnal IImiah Teknik Industri Vol 5 No. 3 April 2007, Universitas Muhammadiyah Surakarta

[4] Hidayat, Nurul. 2013. Optimasi Perencanaan Produksi Dengan Menggunakan Metode Goal Programming (Studi Kasus Pada Usaha Kecil Menengah (UKM) Jipang Ketan Batur Banjarnegara) (Skripsi). Yogyakarta: Universitas Islam Negeri Sunan Kalijaga.

[5] Harjiyanto, Tri. 2014. Aplikasi Model Goal Programing Untuk Optimisasi Produksi Aksesoris (Studi Kasus: PT. Kosama Jaya Banguntapan Bantul) (Skripsi). Yogyakarta: Universitas Negeri Yogyakarta. 